\title{
COMMENTARY
}

\section{Monitoring mortality: a quality improvement perspective}

Guthrie et al's modelling study demonstrates that monitoring mortality in general practices over a period of 3 years is unlikely to detect a murderer who kills fewer than 30 patients.

Monitoring is a method for detecting and acting on signals in data for a range of problems - not just one problem. We monitor patients' temperature postoperatively not just to detect wound infection, but any infection (or even hypothermia). We would certainly miss many infections if we relied solely on temperature. Yet nobody would suggest abandoning the temperature chart. Just as the primary purpose of monitoring the patient's temperature is to improve their health, similarly the primary purpose of monitoring should be quality improvement, not detection of murder. ${ }^{2-4}$

Monitoring serves quality improvement by identifying unusual (special cause) variation, investigating, and learning from such a process. This means systematic investigation to identify data errors, the influence of case-mix, the resourcing, organisation, and delivery of health care. The aim is to learn why mortality might vary and take appropriate action. For mortality differences the most common explanations are unmeasured differences in case-mix. ${ }^{2}$ The actions of individual clinicians are among the last in a series of potential special causes.

Mortality monitoring was one of the recommendations of the Shipman Inquiry. ${ }^{2}$ Others included closer scrutiny of controlled drug prescribing, changes to the coroner system, and more rapid investigation of complaints. The focus on a single recommendation in isolation seems inappropriate.

Could mortality monitoring have a role? Guthrie et al observe that that $85 \%$ of practices in Scotland could be monitored for 10 years, not the 3 years that they model. The NHS's present largely ad hoc and haphazard system failed to detect Shipman's 200 murders. So, detecting even an excess of 30 deaths is better by comparison. However, the focus on seeking murderers is inappropriate. A better question is how often were useful lessons learned from investigating special cause variation? First lessons include correcting data errors and improving understanding of case-mix. Later lessons will be to understand how resourcing and organisation of health care might influence mortality.

Ultimately, quality improvement requires more than monitoring. It requires the trust, commitment, and cooperation of GPs. Any monitoring system that fails on these counts is unlikely to be effective in either securing quality of care or finding 'bad apples'. To start from a position of trust would be for GPs themselves to agree what indicators should be monitored and to decide how they will investigate special cause variation.

\section{Tom Marshall}

Senior Lecturer, Department of Public Health and Epidemiology, University of Birmingham, Edgbaston, Birmingham, B15 2TT.

\section{Mohammed A Mohammed}

Senior Research Fellow, Department of Public Health and Epidemiology, University of Birmingham.

\section{REFERENCES}

1. Guthrie B, Love T, Kaye R, et al. Modelling the effectiveness of routine mortality monitoring in detecting mass murder in UK general practice. Br J Gen Pract 2008: 58(550): 311-317. DOI: 10.3399/bjgp08X280164

2. Shipman Inquiry. The Shipman Inquiry Fifth Report. Safeguarding patients: lessons from the past - proposals for the future. Norwich: HMSO, 2004.

3. Mohammed MA, Booth K, Marshall D, et al. A practical method for monitoring general practice mortality in the UK: findings from a pilot study in a health board of Northern Ireland. Br J Gen Pract 2005; 55: 670-676.

4. Chief Medical Officer. Good doctors, safer patients: proposals to strengthen the system to assure and improve the performance of doctors and to protect the safety of patients. London: Department of Health, 2007.

system to ensure that doctors apply due diligence to accounting for every death appear to have been rejected. ${ }^{6,20}$ Based on this analysis, monitoring mortality rates alone is not enough and cannot substitute for other recommended reforms. ${ }^{4}$ This study did not examine whether it is worth nationally implementing routine general practice mortality monitoring for quality improvement. Although this has some face validity, there is no strong evidence that such a system would improve the quality of care. ${ }^{18}$ However, for the parallel aim of murder detection, then mortality monitoring could at best operate as a backstop to catch a prolific serial killer who has evaded detection by other means.

\section{Commentary}

A commentary accompanies this article: DOI: 10.3399/bjgp08X280173

\section{Funding body}

At the time this work was undertaken, Bruce Guthrie was funded by the Health Foundation and the Chief Scientist Office of the Scottish Executive Health Department, Tom Love by the Chief Scientist Office, and Rebecca Kaye, Jim Chalmers, and Margaret Macleod employed by the Information and Statistics Division of NHS National Services Scotland. The authors were free to publish without any restrictions, and accept full responsibility for the views 